\title{
Selective Cleavage of the Aryl Ether Bonds in Lignin for Depolymerization by Acidic Lithium Bromide Molten Salt Hydrate under Mild Conditions
}

Xiaohui Yang ${ }^{\dagger, \S}$, Ning Li ${ }^{\S}$, Xuliang Lin ${ }^{\S}$, Xuejun Pan ${ }^{\S}, *$, and Yonghong Zhou ${ }^{\dagger}$

${ }^{\dagger}$ Institute of Chemical Industry of Forestry Products, Chinese Academy of Forestry, Nanjing 210042, China

${ }^{\S}$ Department of Biological Systems Engineering, University of Wisconsin-Madison, Madison, WI 53706, USA

*Corresponding author (Tel.: +1-608-2624951; Fax: +1-608-2621228; E-mail: xpan@wisc.edu)

\section{Quantitation of aryl hydroxyl group (ArOH)}

Aryl or phenolic hydroxyl (ArOH) of the lignins was estimated using ${ }^{1} \mathrm{H}$ NMR according to the method reported previously. ${ }^{\mathrm{S} 1} \underline{\underline{\text { ENREF_37}}}$, S2 $\mathrm{In}$ brief, lignin acetate $(50 \mathrm{mg})$ and p-nitrobenzaldehyde (5 mg as internal standard) were dissolved in $0.5 \mathrm{~mL}$ of $\mathrm{CDCl}_{3}$. The ${ }^{1} \mathrm{H}$ NMR spectrum was recorded at $500 \mathrm{MHz}$ with total 128 scans. The content of $\mathrm{ArOH}$ was calculated from integration ratio of the protons of the functional group to the protons of the internal standard. 


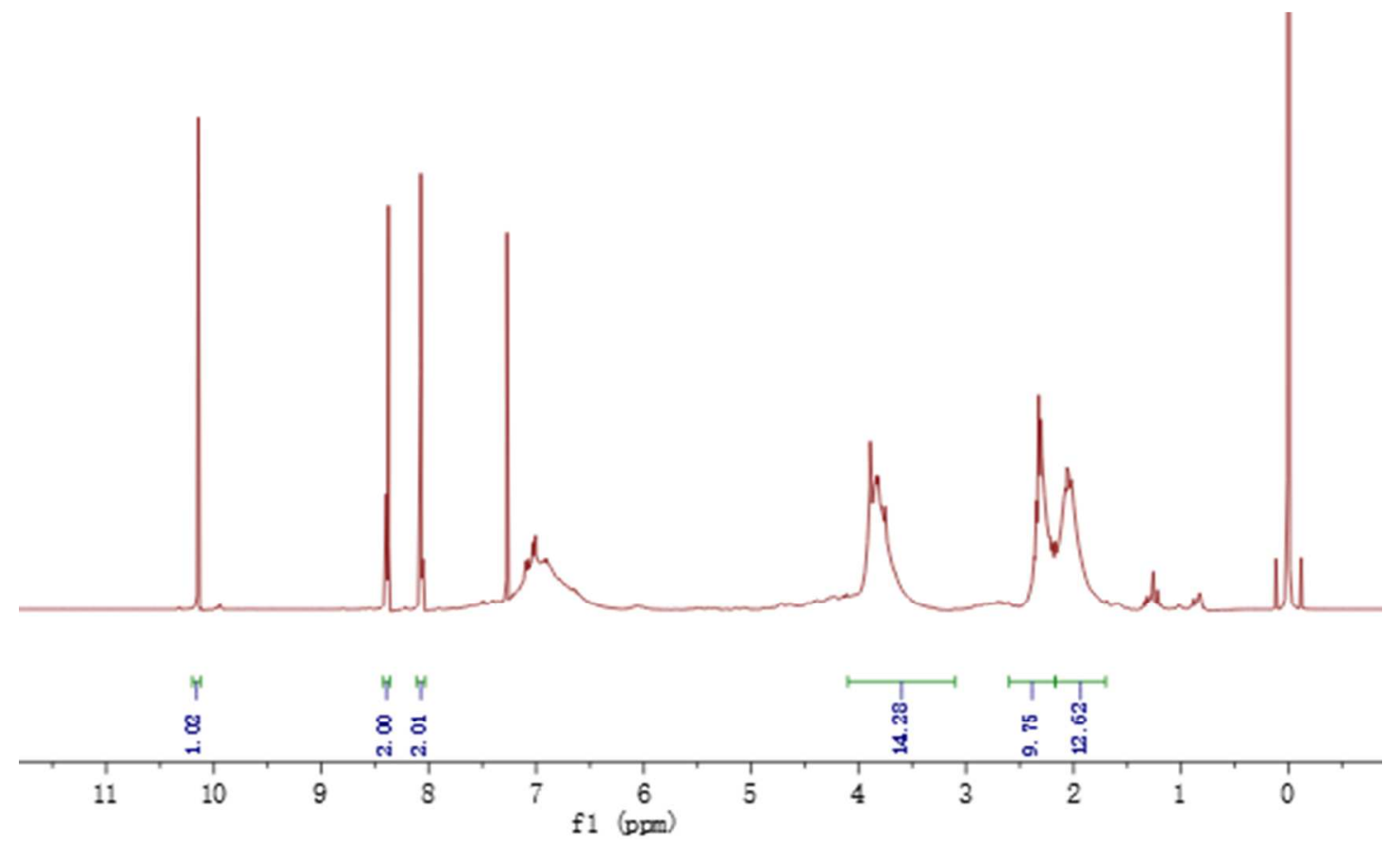

Figure S1. ${ }^{1} \mathrm{H}$ NMR spectrum of SKL acetate in $\mathrm{CDCl}_{3}$ with $p$-nitrobenzaldehyde as internal standard.

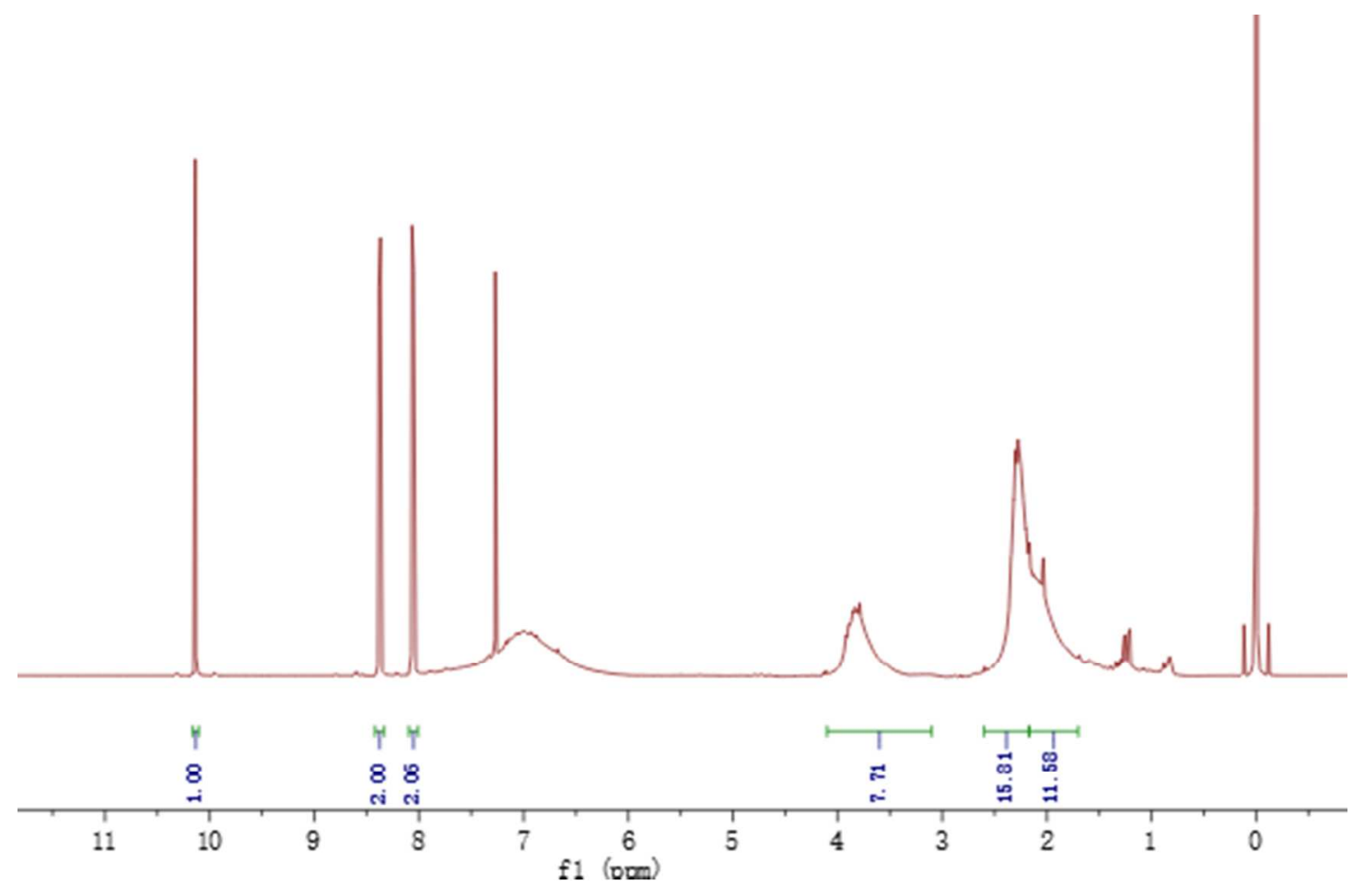

Figure S2. ${ }^{1} \mathrm{H}$ NMR spectrum of TSKL acetate in $\mathrm{CDCl}_{3}$ with $p$-nitrobenzaldehyde as internal standard. 


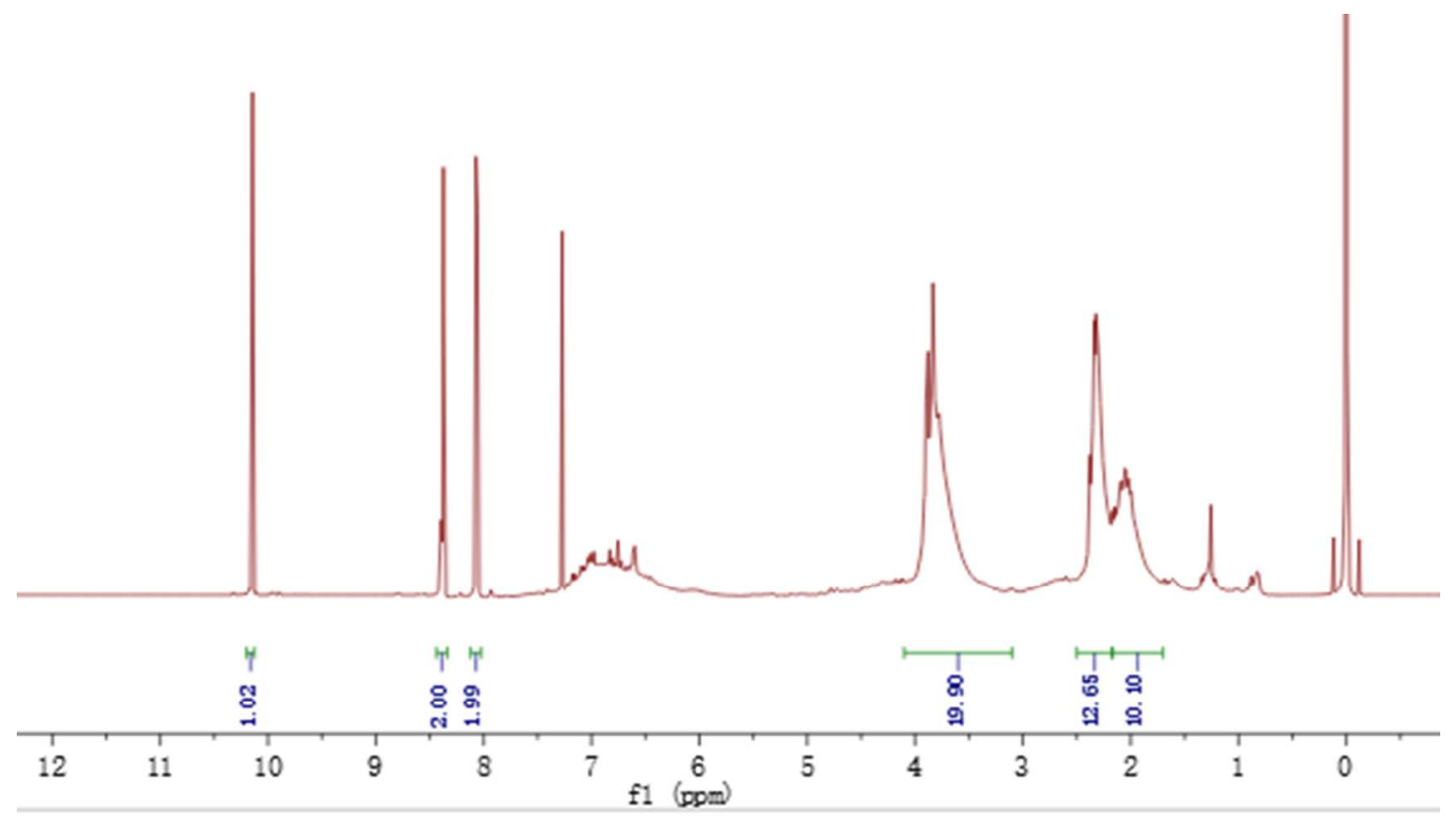

Figure S3. ${ }^{1} \mathrm{H}$ NMR spectrum of $\mathrm{HKL}$ acetate in $\mathrm{CDCl}_{3}$ with $p$-nitrobenzaldehyde as internal standard.

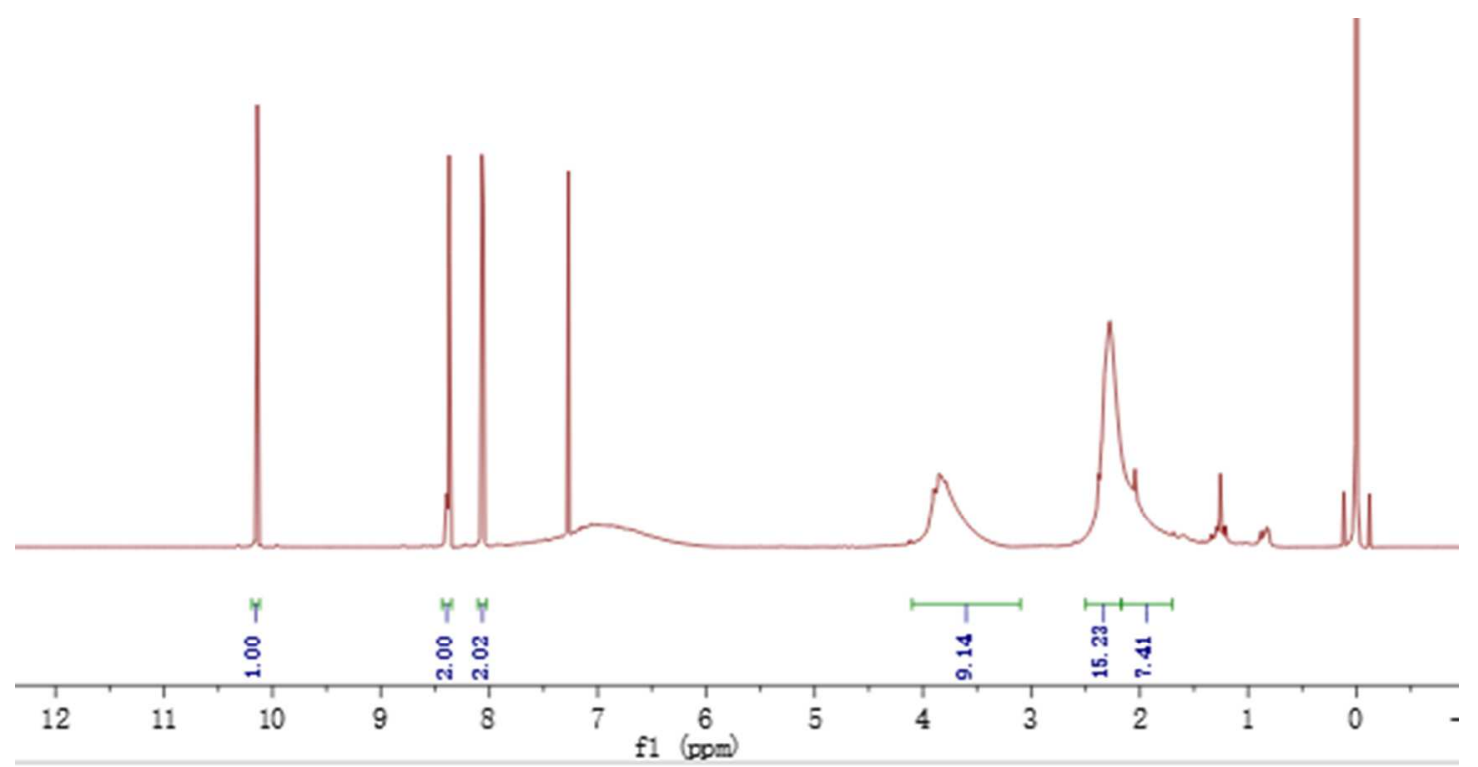

Figure S4. ${ }^{1} \mathrm{H}$ NMR spectrum of THKL acetate in $\mathrm{CDCl}_{3}$ with $p$-nitrobenzaldehyde as internal standard. 


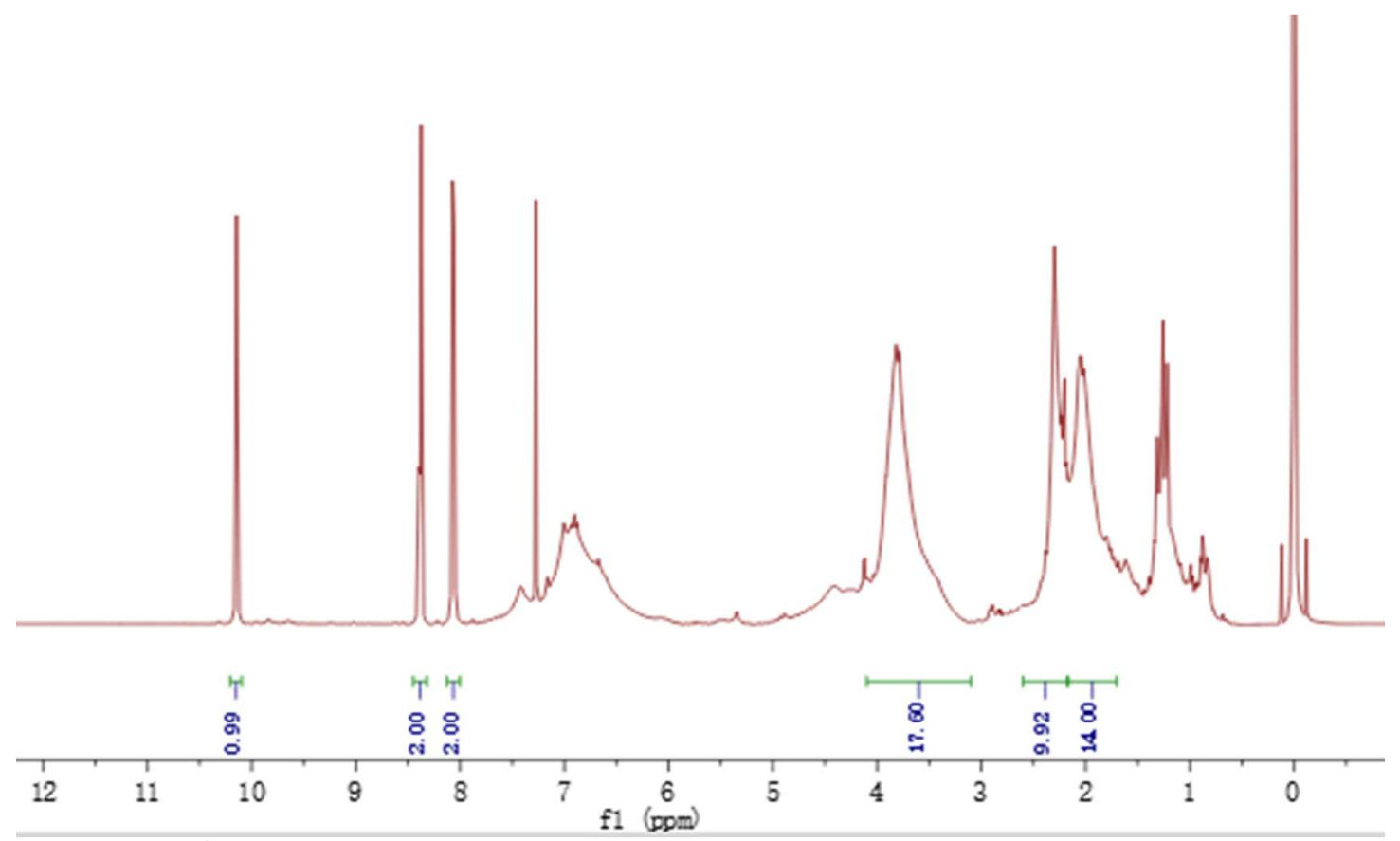

Figure S5. ${ }^{1} \mathrm{H}$ NMR spectrum of EOL acetate in $\mathrm{CDCl}_{3}$ with $p$-nitrobenzaldehyde as internal standard.

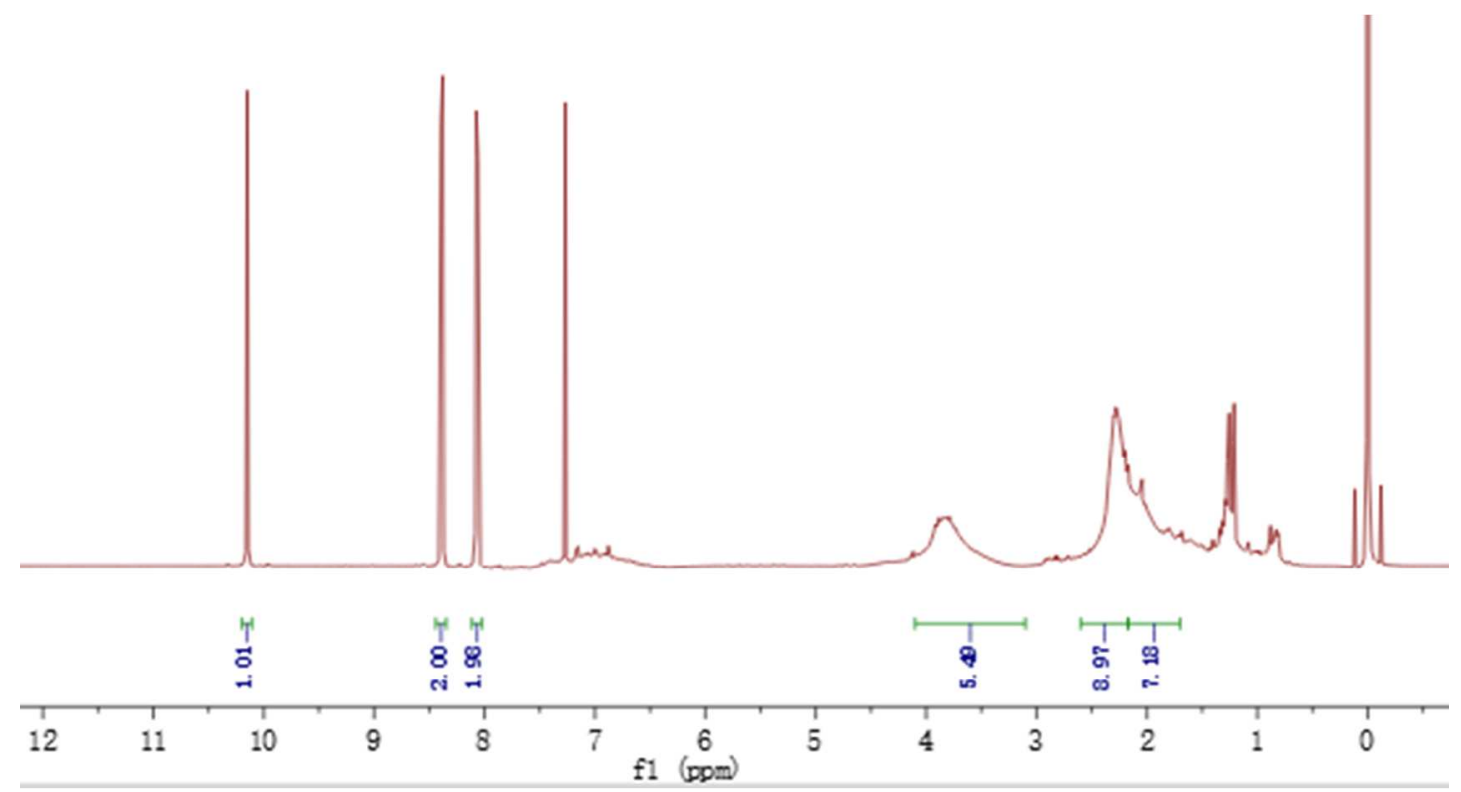

Figure S6. ${ }^{1} \mathrm{H}$ NMR spectrum of TEOL acetate in $\mathrm{CDCl}_{3}$ with $p$-nitrobenzaldehyde as internal standard. 


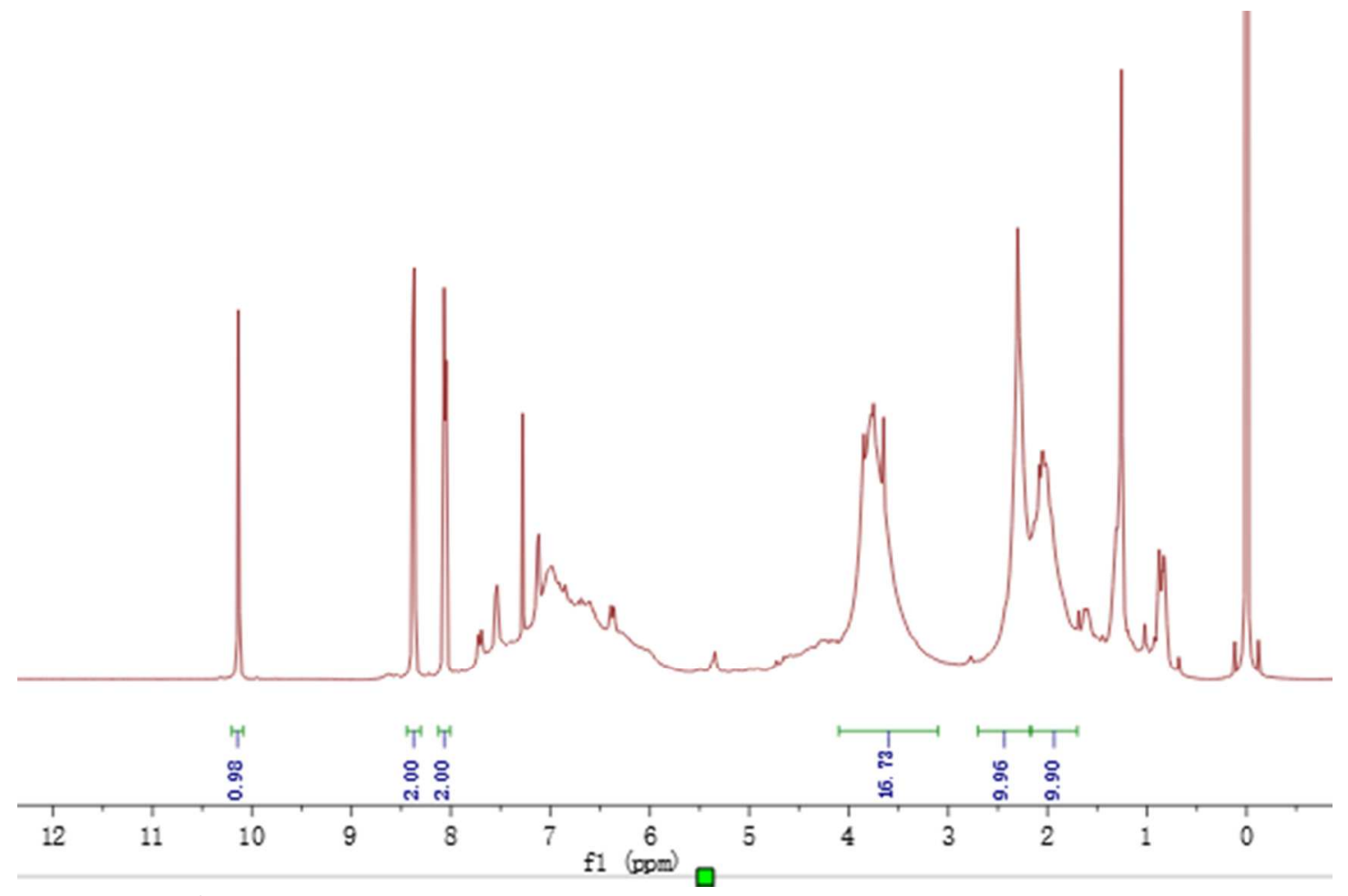

Figure S7. ${ }^{1} \mathrm{H}$ NMR spectrum of $\mathrm{ACL}$ acetate in $\mathrm{CDCl}_{3}$ with $p$-nitrobenzaldehyde as internal standard.

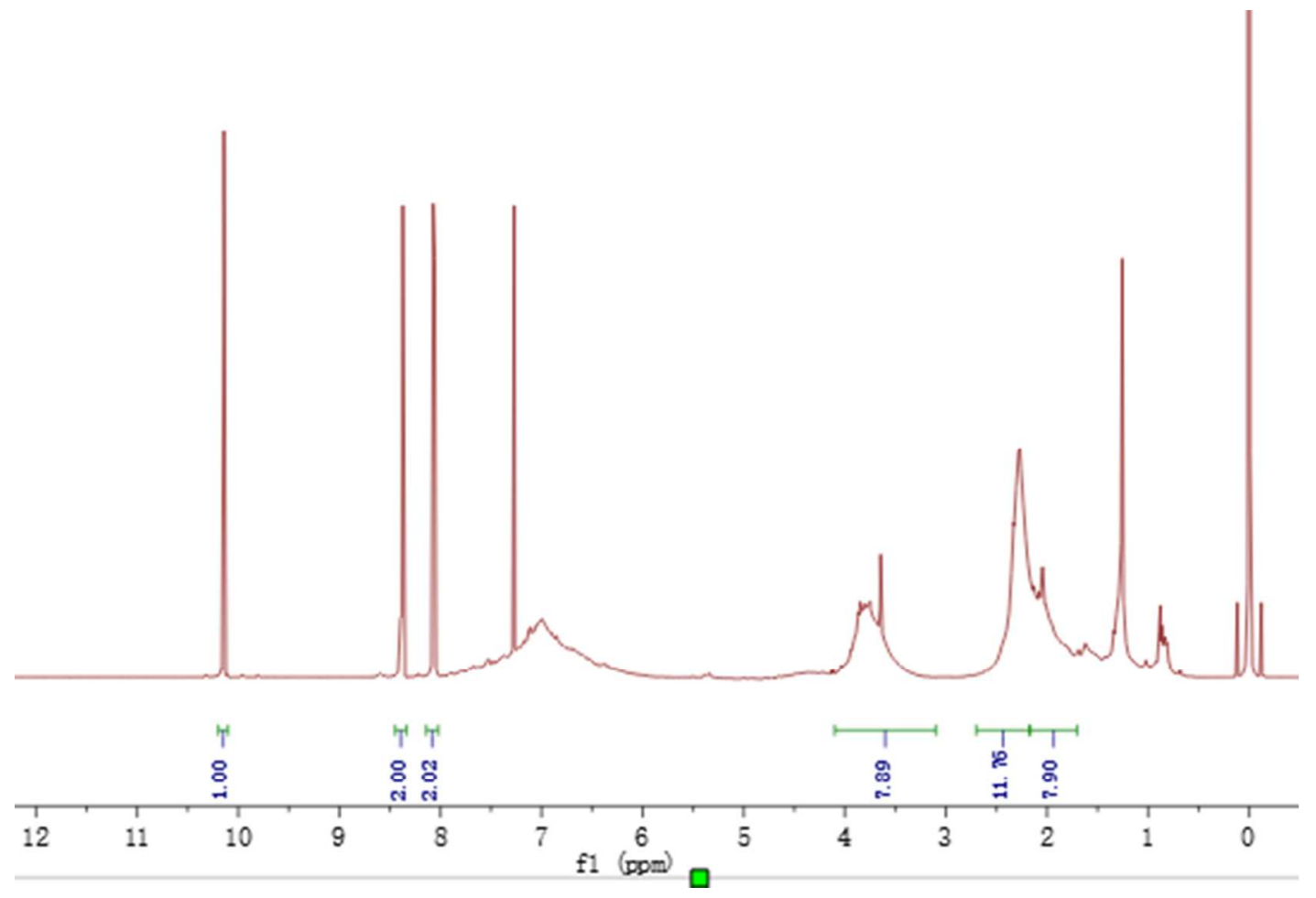

Figure S8. ${ }^{1} \mathrm{H}$ NMR spectrum of TACL acetate in $\mathrm{CDCl}_{3}$ with $p$-nitrobenzaldehyde as internal standard. 

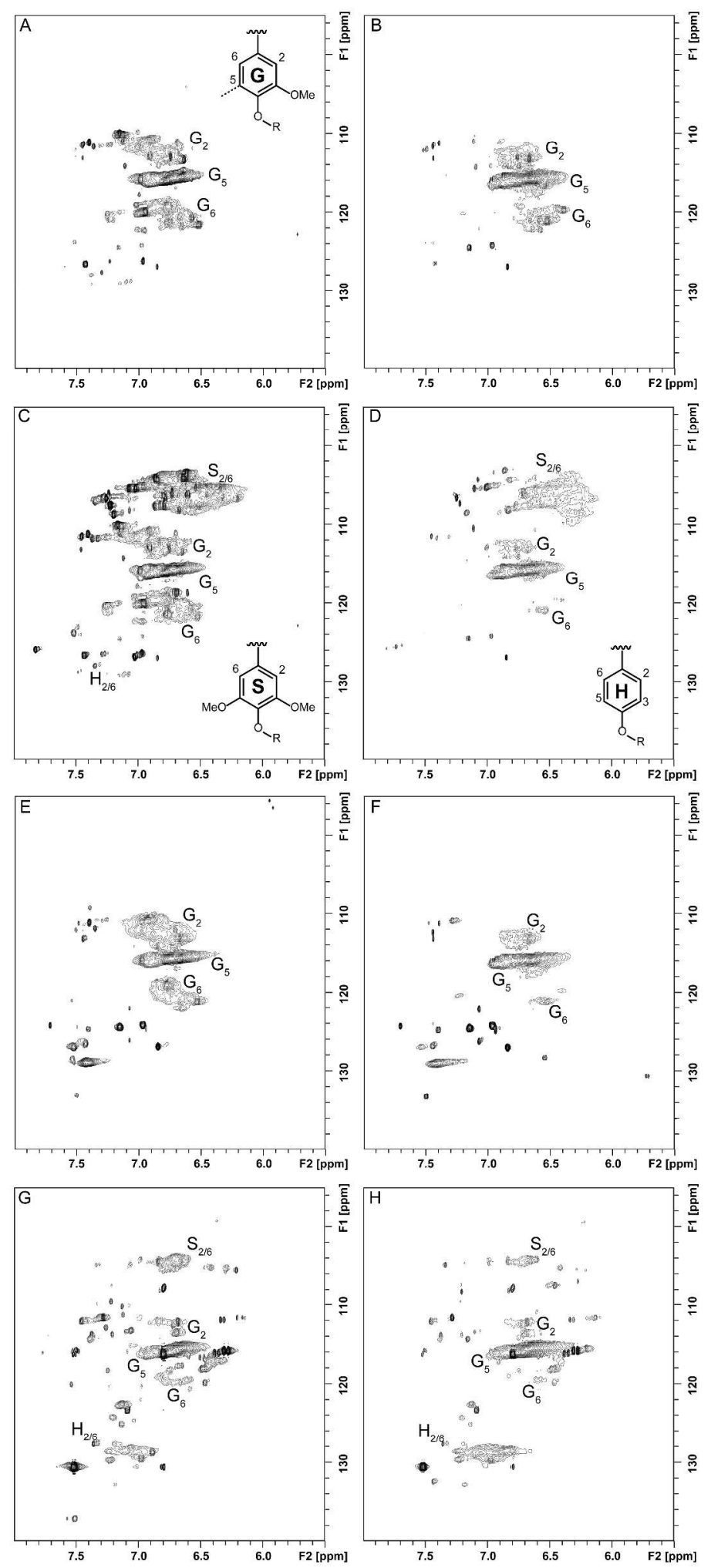

Figure S9. Aromatic region of 2D HSQC NMR spectra of hardwood kraft lignin in DMSO- $d_{6}$ before and after the LiBr treatment. A, SKL; B, TSKL; C, HKL; D, THKL; E, EOL; F, TEOL; G, ACL; and H, TACL. 


\section{REFERENCES}

S1. Pan, X. J.; Kadla, J. F.; Ehara, K.; Gilkes, N.; Saddler, J. N., Organosolv ethanol lignin from hybrid poplar as a radical scavenger: Relationship between lignin structure, extraction conditions, and antioxidant activity. J. Agric. Food Chem. 2006, 54, 5806-5813.

S2. Pan, X. J.; Sano, Y., Atmospheric acetic acid pulping of rice straw IV: Physico-chemical characterization of acetic acid lignins from rice straw and woods. part 2. Chemical structures.

Holzforschung 1999, 53, 590-596. 